\title{
The Effect of Amount of Physical Activity on Cardio Respiratory Fitness and Body Composition
}

\author{
Moradichaleshtori ${ }^{1}$, M., Salami ${ }^{2}$, A., Jafari ${ }^{3}$, A. \\ ${ }^{1}$ Tehran University, \\ ${ }^{2}$ Tarbiat Modares University, \\ ${ }^{3}$ Islamic Azad University, Research and Science Branch, Young Researcher Club.
}

\section{Abstract}

The goal of this study was to assess the effects of amount of ergometer cycle training on $\mathrm{Vo}_{2} \mathrm{max}$ and body composition in overweight women. Forty-one sedentary premenopausal women, age 25 to 45 years, were randomly assigned in three groups. Cycle ergometer training consisted of one day per week for group A, two days per week for group B and three days per week for group C. Participants trained for 60 min in any session with moderate intensity $\left(50-60 \% \mathrm{Vo}_{2} \mathrm{max}\right)$ for 12 weeks. Participants were counseled not to change their diet during the study period. There were no significant differences among variables in three groups at baseline. Means $( \pm \mathrm{SD})$ of weight, body fat, WHR, BMI and $\mathrm{Vo}_{2} \mathrm{max}$ in groups were $67.43 \pm 9.54 \mathrm{~kg}$, $31.56 \pm 4.6$ percent, $0.82 \pm 0.05,25.54 \pm 4.16 \mathrm{~kg} / \mathrm{m}^{2}$ and $31.72 \pm 7.2 \mathrm{ml} . \mathrm{kg}^{-1} \mathrm{~min}^{-1}$ respectively. After 12 weeks, ANOVA test indicated there were significant differences among mean body composition among the three groups. Use of Tukey post-hoc tests showed that difference in theses groups is because of group C. Paired ' $t$ ' test showed that there was significant difference between mean body composition $(\mathrm{p}<0.01)$ in group $\mathrm{C}$. $\mathrm{Vo}_{2}$ max in group $\mathrm{B}$ and $\mathrm{C}$ improved $12 \%$ and $21 \%(\mathrm{p}<0.01)$ respectively with ergometer training. But in group A it was not changed significantly. These findings indicate that the three days in week with 60 min of moderate-intensity, cycle ergometer training is sufficient to improve body composition and $\mathrm{Vo}_{2} \mathrm{max}$ in over weight women. With two days training i.e. $120 \mathrm{~min}$ in a week only, $\mathrm{Vo}_{2} \mathrm{max}$ improved. The results indicate that two days regular training improves $\mathrm{Vo}_{2}$ max in overweight women without change in body composition. With less of amount of physical activity neither body composition nor $\mathrm{Vo}_{2} \mathrm{max}$ improve significantly. These findings strongly suggest that, in the absence of changes in diet, a higher amount of activity is necessary for improving body composition and $\mathrm{Vo}_{2}$ max.

Key words: Overweight, Body composition, Ergometer training, Cardiorespiratory fitness

\section{Introduction}

Obesity and over weight present significant public health concerns because of the link with numerous chronic health conditions (Jakicic, 2003). Also aerobic exercise capacity measured as maximal oxygen uptake $\left(\mathrm{VO}_{2} \max \right)$ is a major predictor of all-cause mortality both in normal and cardiovascular disease subjects (Myers et al, 2002 \& Gulati et al, 2003). Body fat content and $\mathrm{VO}_{2} \max$ are both inversely associated with the risk of cardiovascular diseases and with all-cause mortality. Exercise is an important component of behavioral weight control and cardio respiratory fitness interventions. Recent clinical and epidemiological studies suggest that beneficial effects of regular physical exercise may depend on intensity or amount of work performed during training (Gregg et al, 2003, Lee et al, 2003 \& Rognmo et al, 2004).

Based on studies it is gathered that change in body composition is related more to frequency than to intensity of exercise (Bassulk, 2003 and Chambliss, 2003). Scientific literature indicate that at least 60 minutes of moderate-intensity of physical activity may be necessary to 
maximize weight loss and prevent significant weight regain (Jakicic, 2003; Kemper et al, 2003; Hill \& Wyatt, 2005). But many researches suggest that high-intensity training is more effective in improving cardio respiratory fitness $\left(\mathrm{Vo}_{2} \mathrm{max}\right)$ than moderate-intensity training (Caspersen et al, 1985 \& Chambliss, 2003). Many over weight women can not be trained at high intensity level and prefer moderate level of physical activity. On the other hand for individuals constrained by a busy lifestyle, an exercise prescription that delivers benefits with the minimum investment of days is attractive (Jakicic, 2003), therefore the goal of this study was to assess the effects of amount of ergometer cycle training on $\mathrm{Vo}_{2}$ max and body composition in over weight women.

\section{Material and Methods}

This study has been completed in Tehran University of Tehran. Inclusion criterion were gender female, age (25-45 years), BMI (25-30 $\mathrm{Kg} / \mathrm{m}^{2}$ ) and freedom from serious concurrent medical or psychological problems. Forty-one sedentary premenopausal women were randomly assigned in three groups. Cycle ergometer training consisted of one day per week for group A, two days per week for group B and three days per week for group $\mathrm{C}$. Participants trained $60 \mathrm{~min}$ in any session with moderate intensity $(50-60 \%$ $\mathrm{VO}_{2} \max$ ) for 12 weeks. There were no significant differences among variables in three groups at baseline. Subjects provided written informed consent to participate in this study.
Participants took 60 minutes of cycle ergometeric training at 50-60\% $\mathrm{VO}_{2}$ max for 12 week. It means that first group took one day in a week of 60 minutes of cycle ergometer training; second group took two days in a week equal to 120 minutes and third group took three days in week of 180 minutes of cycle ergometer training per week. The training was completed on a cycle ergometer (Monark), and heart rate was monitored, so as to control the intensity of the exercise training. During intervention, skilled exercise experts controlled the participant's training on cycle ergometer and provided encouragement and support to the participants for continuing the exercise program. All the participants were asked not to change their eating habits during the intervention period, and food diaries were kept and monitored weekly.

Height and weight were measured (shoes off) using a balance beam scale. Body mass index was calculated by dividing weight (kilograms) by height squared (meters square). The waist measurement was taken at the narrowest part of the torso between the rib cage and the iliac crest, after a normal expiration. Hip circumference was measured at the greatest gluteal protuberance while the subject stood with the feet together.

Percent body fat was measured by the using skin fold calipers (baseline) at three sites (triceps, subscapular \& abdomen). $\mathrm{Vo}_{2}$ max was predicted by sub maximal Astrand test on cycle ergometer.

All the tests were repeated after the completion of 12-weeks of ergometer training.

Data analyses for this study were done by using SPSS statistical software 
(version 11.0). Significance was set at $P<0.05$ for all tests. Analyses of the dependent variables (i.e., weight, BMI, percent body fat, and waist and hip circumferences) were performed in 2 steps. First, ANOVA was utilized to determine whether body composition and $\mathrm{Vo}_{2} \max$ variables varied across activity groups. Tukey post-hoc tests was applied to find the the groups that differed from each other in statistical terms. Paired' $t$ ' test was applied to evaluate the effect of twelve weeks of cycle ergometer training in statistical terms on the body composition and $\mathrm{VO}_{2} \max$ in the the three groups.

\section{Results}

Baseline characteristics of the subjects' belonging to the three groups before the the start of the training program are presented in table 1 .

Table 1: Subject Characteristics at Baseline for all groups

\begin{tabular}{lcccccc}
\hline & \multicolumn{2}{c}{ First Group } & \multicolumn{2}{c}{ Second Group } & \multicolumn{2}{c}{ Third Group } \\
& Mean & \pm SD & Mean & \pm SD & Mean & \pm SD \\
\hline Body Weight (kg) & 67.00 & 9.10 & 67.04 & 9.10 & 68.40 & 10.70 \\
\%t body fat & 30.84 & 5.30 & 31.90 & 5.01 & 31.10 & 4.20 \\
BMI (Kg/m2) & 24.44 & 3.30 & 25.78 & 3.02 & 26.50 & 2.35 \\
WHR & 0.82 & 0.03 & 0.81 & 0.07 & 0.82 & 0.06 \\
Vo2max & 31.84 & 5.30 & 29.90 & 5.01 & 30.10 & 4.20 \\
\hline
\end{tabular}

All participants completed the 12week program of exercise. The analysis of variance showed neither significant interactions nor differences among groups with regard to weight, body fat, WHR, $\mathrm{BMI}$ at baseline.

Means $( \pm \mathrm{SD})$ of post-test weight, body fat, WHR, BMI in all the groups are shown in Table 2. After 12 weeks, ANOVA test indicated there was significant difference among mean body composition among the three groups. Use of Tukey post-hoc tests showed that difference in theses groups is because of group C. Paired ' $t$ ' test showed that there was significant difference in mean body composition $(p<0.01)$ in group $C$. These tests were used for $\mathrm{Vo}_{2} \max$ too. Paired ' $\mathrm{t}$ ' test showed that $\mathrm{Vo}_{2}$ max in group $\mathrm{B}$ and $\mathrm{C}$ improved $12 \%$ and $21 \% \quad(\mathrm{p}<0.01)$ respectively. But in group $\mathrm{A}$ it did not change significantly.

\begin{tabular}{|c|c|c|c|c|c|c|c|}
\hline & \multicolumn{2}{|c|}{ First Group } & \multicolumn{2}{|c|}{ Second Group } & \multicolumn{2}{|c|}{ Third Group } & \multirow{2}{*}{$\mathbf{P}$} \\
\hline & Mean & SD & Mean & SD & Mean & SD & \\
\hline $\begin{array}{l}\text { 3ody Weight } \\
\text { kg) }\end{array}$ & 66.45 & 9.05 & 67.10 & 8.50 & 66.50 & 9.80 & 0.03 \\
\hline$\%$ t body fat & 32.67 & 4.40 & 31.40 & 4.30 & 29.95 & 3.90 & 0.03 \\
\hline BMI (Kg/m2) & 28.28 & 3.40 & 26.65 & 2.80 & 25.02 & 2.40 & 0.03 \\
\hline WHR & 0.82 & 0.04 & 0.79 & 0.05 & 0.78 & 0.05 & 0.02 \\
\hline Vo2max & 32.14 & 3.30 & 34.90 & 4.07 & 38.10 & 5.00 & \\
\hline
\end{tabular}

\section{Discussion}

This study investigated the effect of number of ergometer cycling days in a week on body composition and $\mathrm{Vo}_{2} \max$. The findings indicate that three days in a week with $60 \mathrm{~min}$ of moderate-intensity cycle ergometer training is sufficient to improve body composition and $\mathrm{Vo}_{2}$ max in over weight women. With two days training $(120 \mathrm{~min})$ in a week, only $\mathrm{Vo}_{2}$ max improved, so two days regular training without change in body composition is a useful strategy for improving $\mathrm{Vo}_{2}$ max in overweight women. With less of this amount neither body composition nor $\mathrm{Vo}_{2} \max$ improve significantly. The data showed importance of the amount of training in a week. Amount of physical activity time to change body composition is in accordance 
with IOM report (2002) that recommended 60 minutes of daily moderate intensity physical activity. Current population - level recommendations for levels of physical activity from the Centers for Disease Control and Prevention are also the same i.e. exercise of moderate or greater intensity per week (Pate et al, 1995). In the present study the first and second groups who were engaged for 60 and 120 minutes of physical activity per week did not reveal changes in the body composition. According to our study the exercising subjects in the third group who underwent 60 minutes of cycle ergometer training for three days a week showed significant reduction in body weight, percent body fat, body mass index, WHR while the values for the rest of the groups' actually decreased slightly over the same time frame. The fact that first and second groups of the present study did not lose weight is supported by other research studies that generally reveal that weight loss needs at least 150 minutes of moderate intensity of exercise per week (Saris et al, 2003). Dutch standard for healthy levels of exercise also stipulates a minimum of thirty minutes of moderate exertion for adults preferably every day but on no less than five days per week (Kemper et al, 2003).

Secondly, our results suggest that two and three 60-min days of moderateintensity training in a week significantly improve $\mathrm{Vo}_{2}$ max but one day training in a week is not sufficient to change $\mathrm{Vo}_{2}$ max. This finding is consistent with those of previous researchers (Macfarlane et al, 2006) who demonstrated the efficacy of 150 min of exercise training. Based on the results of the present and earlier studies, the health benefits of physical activity on $\mathrm{Vo}_{2}$ max are believed to relate more to the exercise intensity than to the volume (Kemia et al, 2005). Several publications report that the cardiovascular effects vary with the intensity or amount of exercise (Wisløff et al, 2005) and some investigations indicate that this amount and intensity of exercise should be sufficient in order to improve $\mathrm{Vo}_{2}$ max (Myers et al, 2002).

Thirdly results of some investigators disclose that physical exercise alone without dieting (caloric restriction) has a modest effect on total body mass and fat loss (Bouchard et al, 1993; Després and Lamarche, 1993; Stefanick, 1993) and helps to maintain weight loss and prevent weight regain $(\mathrm{NIH}, 1996$ \& Wing \& Hill, 2001). However in the present study subjects were requested not to change their dietary habit, it is possible that by reducing calorie intake they would have improved their body composition more. Many studies have divulged that over weight or obese people lose weight and improve in body composition better with a combination of dietary and exercise regimen than with dietary or exercise regimen alone (Després and Lamarche, 1993 \& Chambliss, 2003).

These findings strongly suggest that, in the absence of dietary restrictions, a higher amount of activity is necessary for improving the body composition and $\mathrm{Vo}_{2}$ max. It is suggested that to have greater improvements in health and fitness one needs to increase the duration or days of physical activity alongwith creation of daily calorie intake deficit. 


\section{References}

Bassulk, Shair, S. 2003. Physical activity and cardiovascular disease prevention in women: How mach is good enough? Exercise \& Sport Science Reviews, 31(4): 176-181.

Bouchard, C., Despres, J. P. and Tremblay, A. 1993. Exercise and obesity. Obes. Res., 1: 133-147.

Caspersen, C.J., Powell, K.E., Christenson, G.M. 1985. Physical activity, exercise, and physical fitness: definitions and distinctions for health-related research. Public Health Rep., 100: 126-31

Chambliss, H.O. 2003. Exercise duration and intensity in a weight-loss program. JAMA, 290(10):1323-30.

Després, J. P., and Lamarche, B. 1993. Effects of diet and physical activity on adiposity and body fat distribution: implications for the prevention of cardiovascular disease. Nutr. Res. Rev., 6: 137159.

Gregg, J.A., Cauley, K., Stone, T.J., Thompson, D.C. Bauer and Cummingsm S.R. 2003. Relationship of changes in physical activity and mortality among older women, JAMA, 289: 2379-2386.

Gulati, D.K., Pandey, M.F., Arnsdorf, D.S., Lauderdale, R.A., Thisted and Wicklund, R.H. 2003. Exercise capacity and the risk of death in women. The St James women take heart project, Circulation, 108: 1554-1559.

Hill, J.O., \& Wyatt, H.R. 2005. Role of physical activity in preventing and treating obesity. J Appl. Physiol., 99(2): 765-70.

Jakicic, J.M., 2003. Exercise in the treatment of obesity. Endocrinal. Metab. Clin. North Am., 32(4): 96780

Kemia, Per M., Harama, Jan P., Loennechenb, Jan-Bjørn Osnesc, Tor Skomedalc, Ulrik Wisløffa, b and Øyvind, Ellingsen 2005. Moderate vs. high exercise intensity: Differential effects on aerobic fitness, cardiomyocyte contractility, and endothelial function. Cardiovascular Research, 67(1): $161-172$

Kemper, H.C.G., Stasse, W. M., \& Bosman, W. 2003. The prevention and treatment of overweight and obesity: Summary of the advisory report by the Health Council of the Netherlands. The
Netherlands Journal of Medicine, 104: 16941740.

Lee, H.D. Sesso, Y. Oguma and R.S. Paffenbarger Jr. 2003. Relative intensity of physical activity and risk of coronary heart disease, Circulation, 107: 1110-1116.

Macfarlane, D.J., Taylor, L.H., Cuddihy, T.F. 2006. Very short intermittent vs continuous bouts of activity in sedentary adults. 43(4): 332-336

Myers, M. Prakash, V. Froelicher, D. Do, S. Partington and Atwood, E. 2002. Exercise capacity and mortality among men referred for exercise testing, N. Engl. J. Med., 346: 793-801.

NIH, 1996. Consensus Development Panel on Physical Activity and Cardiovascular Health: Physical activity and cardiovascular health.. JAMA, 276: $241-246$.

Pate, R.R, Pratt, M, Blair S.N., Haskell, W.L., Macera, C.A., Bouchard, C., Buchner, D., \& Ettinger, W., 1995. Physical activity and public health: a recommendation from the Centers for Disease Control and Prevention. American College of Sports Medicine. JAMA, 273: 402 -407.

Rognmo, E. Hetland, Helgerud, J., Hoff, J. and Slørdahl, S.A. 2004. High intensity aerobic interval exercise is superior to moderate intensity exercise for increasing aerobic capacity in patients with coronary artery disease, Eur. $J$. Cardiovasc. Prev. Rehabil., 11: 216-222.

Saris, W.H., Blair, S.N., \& Vanbaak, M.A., 2003. How much physical activity is enough to prevent unhealthy weight gain? Outcome of the IASO 1st Stock Conference and consensus statement. Obes. Rev. 4(2): 101-14

Stefanick, M. L. 1993. Exercise and weight control. In: Exercise and Sport Sciences Reviews, Vol. 21, Ed. Holloszy, J. O. Baltimore: Williams \& Wilkins, pp. 363-396

Wing R.R., \& Hill J.O. 2001. Successful weight loss maintenance. Annu. Rev. Nutr., 21: 323-341.

Wisløff, S.M. Najjar, Ø. Ellingsen, P.M. Haram, S. Swoap and Al-Share, Q. 2005. Cardiovascular risk factors from artificial selection for low aerobic capacity in rats, Science, 307, 418-420. 